\title{
SELF-TALK DOES NOT AFFECT THE TRANSFER AND RETENTION IN THE TENNIS FOREHAND LEARNING IN BEGINNERS
}

\author{
Thiago Rogel Santos Ferreira ${ }^{1,2}$, Flávio Henrique Bastos ${ }^{2}$, Silmara Cristina Pasetto ${ }^{2,3}$, \\ Camila Torriani-Pasin'², and Umberto Cesar Corrêa ${ }^{2}$ \\ ${ }^{1}$ Metropolitan University of Santos; Santa Cecilia University, Brazil \\ ${ }^{2}$ Motor Behavior Laboratory, University of São Paulo, Brazil \\ ${ }^{3}$ Hermínio Ometto University, Brazil
}

Original scientific paper

UDC: $159.954 .4: 796.342$

\begin{abstract}
:
The aim of this study was to investigate the effects of self-talk on motor learning in beginners. The learning task was the forehand stroke in tennis. Eighty-four students were assigned into five self-talk groups and one control group. One of the self-talk groups used four cues for directing attention to key elements of the forehand stroke. The other self-talk groups made use of only one of the four cues (ball, bounce, hit, and ready), and the control group received only general instructions. In the acquisition phase, all groups performed 180 trials over three days. Then they performed a transfer test of 10 trials involving a change in the target direction. After five days they performed a retention test in the same conditions of the acquisition phase. The performance was analysed in terms of rates of success and consistency of the forehand hit to the target located on the opponent's court. Results showed that all groups improved their performances in the acquisition phase, and that they maintained the improvement in the retention and transfer tests. However, no differences were found between the groups. It was concluded that self-talk did not affect the learning of forehand stroke in tennis. In addition, learning with self-talk with four cues was similar to that with selftalk with only one cue.
\end{abstract}

Key words: selective attention, motor skill learning, instruction, cues, racket sports

\section{Introduction}

People talk out loud to themselves all the time. For instance, they do this in order to express a concern when performing a motor task (e.g. I won't get it), as a motivation in performing it (e.g. I can), or to pay attention on a task's relevant information. This phenomenon of verbalizing to oneself words or short and concise phrases has been named self-talk.

In the last few years, self-talk has been recognized in the field of sports as a useful strategy for promoting an increase in motivation (self-encouragement, self-confidence, and coping) and attentional focus (mental readiness, arousal regulation, information processing) (Hardy, Hall, \& Hardy, 2004; Hatzigeorgiadis, Theodorkis, \& Zourbanos, 2004, 2011; Weinberg, Miller, \& Horn, 2012; Zervas, Stavrou, \& Psychountaki, 2007; Zourbanos, Theodorakis, \& Hatzigeorgiadis, 2006). Such selftalk benefits have been considered in terms of two main categories: motivational and instructional. The motivational self-talk would contribute to neutrali- zing and inhibiting anxiety at execution time. On the other hand, of concern in this study, the instructional self-talk would either help an individual to focus on a relevant information regarding the execution of a motor task or not to repeat mistakes of the past (Burton, Gillham, \& Glenn, 2011; Hardy, 2006; Hatzigeorgiadis, et al., 2011; Theodorakis, Weinberg, Natsis-Douma, \& Kazakas, 2000; Zervas, et al., 2007). Importantly, the aforementioned self-talk effects are closely related to another self-talk category, namely, valence. Accordingly, self-talk may be categorized as both positive and negative. Positive self-talk involves an encouraging or positive voice tone, and the tone of the negative self-talk reflects anger, frustration, or discouragement (Van Raalte, Vincent, \& Brewer, 2016).

These dimensions have been the foci of a number of studies (e.g. Hatzigeorgiadis, et al., 2004; Weinberg, et al., 2012). For instance, Hatzigeorgiadis et al. (2004) investigated the effects of self-talk as instructional and motivational strate- 
gies on disturbing thoughts and on performance of two types of water polo throwing: at a target (exp. 1) and for a distance (exp. 2). Individuals were assigned into three groups: (1) instructional self-talk, with the "ball-target" cue, (2) motivational self-talk, saying, "I can", and (3) control. All groups performed a pre-test without self-talk and, after two weeks, groups 1 and 2 performed a re-test with self-talk. The results have shown that groups using self-talk had lower interference of irrelevant thoughts to the task by increasing concentration, based on a comparison to the control group. Interestingly, superior performance was also verified for the groups that used the instructional self-talk.

Although these results provided some support for the beneficial effects of self-talk, they have not been extended to a variety of tasks, considering its specificity. In fact, the literature has shown that self-talk affects fine motor skills more than gross motor skills, as was the case in the study by Hatzigeorgiadis et al. (2011) study. Fine motor skills are those that demand precision in movement and involve small muscle groups. On the other hand, gross motor skills require the use of relatively large musculature in producing a movement. They typically involve many muscle groups and, frequently, movement of the entire body (Edwards, 2010).

Another important finding from the selftalk literature is that it also affects the "learning process" of motor skills. Specifically, it has been suggested that self-talk has effects mainly on the early stages of learning (Cutton \& Landin, 2007; Hatzigeorgiadis, et al., 2011; Landin, 1994; Zervas, et al., 2007). In fact, one could say that the seminal study on self-talk in the field of sports was related to motor skill learning. Ziegler (1987) investigated the use of self-talk on the learning of forehand and backhand of field tennis. In this study, the instructional self-talk referred to cues for directing attention to critical points of the motor skills. The research was carried out within a tennis initiation programme and had two practice sessions by week for 10 weeks. Novice college students took part in the experiment and were assigned into three groups differing among thenselves with regard to the moment in which self-talks were entered during practice. Four cues were used. Cue 1 oriented the learner to identifying the stimulus, so he/she should say the word "ball" to detect the moment in which the ball was thrown by a launcher machine. Cue 2 guided the player's attention to tracking the stimulus, and the word "bounce "was verbalized during the contact of the ball with the floor, helping the player to select the appropriate response. The word "hit "directed the player's attention to paddle contact with the ball, specifically to the programming of a response (cue 3). After the execution of hitting, the participant said the word "ready" to direct attention to the starting point (cue 4). The results pointed to the performance improvement after inserting the selftalk cues and, interestingly, this occurred despite the absence of teacher's feedback.

Nevertheless, in spite of the existing evidences, the self-talk benefits are not without their criticism, especially with respect to motor skill learning. This is because most of the studies present serious methodological limitations for advancing the specific knowledge; that is, not all of them have used retention and transfer tests in their experimental designs (e.g. Cutton \& Landin, 2007; Ziegler, 1987). The lack of such tests does not allow the generalization of findings to the learning of motor skills; namely, the tests function to separate the temporary effects of performance from those that promote to permanent learning (Edwards, 2010; Magill, 2010; Schmidt \& Lee, 2011, Singer, 1980). To put it in another way, the fact that few studies involving tasks and learners with distinct characteristics have used learning tests (e.g. Zetou, Vernadakis, Bebetsos, \& Makraki, 2012; Zetou, Vernadakis, \& Bebetsos, 2014a; Zetou, Vernadakis, Bebetsos, \& Liadakis, 2014b) raises the need of further investigation in order to add consistency to this scientific knowledge.

Additionally, one could question the amount of self-talk cues provided to the beginning learners. Learners at an early stage of learning are unable to select the critical information for performing a motor skill with success, or to deal with two or more pieces of information at the same time (Denardi \& Corrêa, 2013; Magill, 2010; Pasetto, Araújo, \& Corrêa, 2006; Schmidt \& Lee, 2011). Based on this statement, it appears reasonable to suppose that selftalk cues can help learners to focus their attention on necessary information (Cutton \& Landin, 2007; Hatzigeorgiadis, et al., 2011; Landin, 1994; Zervas, et al., 2007; Ziegler, 1987). Even more, self-talk cue could be seen as an individualized strategy of selective attention (Landin, 1994). However, these same learners' characteristics allow one to hypothesize that providing a large amount of sequential self-talk during performance (e.g. Cutton \& Landin, 2007; Ziegler, 1987) could mean an overload of information for the learner to process and, therefore, have a negative effect on motor learning. In other words, if the amount of information is large, the reserve of central resources for attention can be exceeded and the system might collapse (Kahnemam, 1973). Hence, the present study aimed to investigate the following specific questions: Would the effects of self-talk on beginners' performance be confirmed in learning tests? and Would providing several selftalk cues to the beginning learners overload their attentional capability? We hypothesized that (i) the practice with self-talk would lead to better learning than that without self-talk, and (ii) self-talk with only one aspect of the task would lead to the improved learning as compared to self-talk with several cues. 


\section{Methods}

\section{Participants}

Volunteer college students, both male $(n=48)$ and female $(\mathrm{n}=36)$, of an average age of 24.69 years $( \pm 3.97)$, took part in this experiment. Participation required the learner's written consent. The study was approved by the Institutional Review Board for the protection of human subjects. The inclusion criteria were that the participants have not had any involvement with systematic practice of tennis, as well as experience with the practice of any other racquet sport.

\section{Task and equipment}

The forehand of the field/court tennis was used as the learning task. This motor skill made it possible for us to place the attentional focus and to track sequential components of performance (selftalked). For this reason, this motor skill has been used in studies of self-talk (Cutton \& Landin, 2007; Ziegler, 1987). The task consisted of hitting a ball (forehand) thrown by a machine positioned behind and in the middle of the end line of the opponent's court. The speed of the ball was $50 \mathrm{~km} / \mathrm{h}$. The task goal was to hit with the ball a square target $\left(20 \mathrm{~m}^{2}\right)$ positioned at the bottom of the opponent's court, at the opposite side of the learner, i.e. diagonally from him/her (Figure 1), and farther than $16 \mathrm{~m}$. The target position was changed to the left or right according to the learner's manual preference.

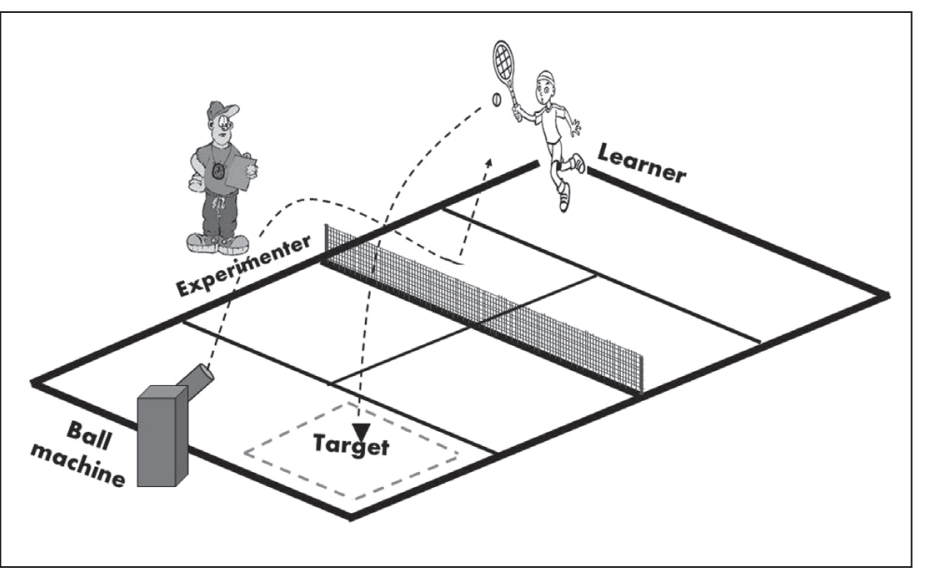

Figure 1. Illustration of the data collection experimental environment. according to specificity of the verbalized cue, similarly to those used in the Ziegler's (1987) seminal study. They were the words "ball", "bounce", "hit", and "ready".

The word "ball" was verbalized in order to direct the learner's attention to the ball fired from the machine ("ball" group). "Bounce" was said to direct the player's attention to the contact of the ball with the floor ("bounce" group). To focus attention on the ball contacting the racquet, the learners verbalized the word "hit" ("hit" group). Finally, the learners said "ready" to prompt them to receive the next ball ("ready" group). Similar to the Ziegler's (1987) study, each self-talk cue had a specific function, that is, to direct the learner's attention to a specific component/dimension of the task. While the word "ball" oriented the learner to identifying the stimulus, specifically to the moment the ball was thrown by a launcher machine, the cue "bounce" guided his/her attention to tracking the stimulus and, consequently, helped him/her to select the appropriate response. The cue "hit" directed the learner's attention to paddle contact with the ball and, therefore, to the programming of a response. Finally, the learner verbalized "ready" to direct attention to the starting point, preparing him/her for the next trial. The two other groups were the "whole" group, in which the learners verbalized each of the cited words according to their requirements (ball - bounce - hit - ready), and the "control" group, which did not use self-talk.

The study included three phases: acquisition, transfer and retention. The acquisition phase consisted of 180 trials divided into three blocks of twenty trials per day. The interval between trials was five seconds, and the interval between blocks was three minutes. The frequency of self-talk was $100 \%$.

Before starting each block of trials, all groups received general instructions in order to understand the forehand skill and the task goal. The information was standardized and provided through verbal instruction and demonstration, as follows: "Take the racket as if to greet it. Keep your feet parallel and the head of the racket above your wrist line. The foot opposite to the hand that is holding the racquet must stay in front, with the body in lateral position". After hearing these instructions, the learners watched a 40 -second video containing images of a player performing the task. Furthermore, before starting the blocks of trials, participants had the opportunity to perform three hits to acquaint themselves with the task.

An experimenter was positioned between a learner and the target in order to verify if the learner talked as he/she had been instructed and to record his/her performance. Learners were asked 
to perform self-talks loudly. The experimenter informed them when an omission occurred or the speech was not loud enough. This procedure was necessary because the mandatory self-talk caused some discomfort in learners, omission or error in verbalizing, in particular in the first block of trials. In the following blocks, there was a reduction of the dissatisfaction, as if self-talk had become automated according to participants' reports. This discomfort was greater in the group using the four cues and lower in the group that used the hit cue. Interestingly, even when the learner did not run the selftalk (transfer/retention tests), the group "hit" kept making use of the strategy.

The transfer test was applied on the last day of the acquisition phase, after the ten-minute interval. This test involved 10 trials in a situation in which the target was positioned parallel to the learner. The retention test was carried out five days after the acquisition phase and under the same conditions.

It is important to highlight that the variables manipulated in this method were tested previously in pilot studies.

\section{Statistical analysis}

Data were recorded according to the success of performance (hitting the target). They were analysed in relation to rates of success and consistency of performance in the first and last acquisition blocks, and in the transfer and retention blocks. The rate of success was calculated by the following equation: $T x S=(n S / n T t) x 100$, where $T x S$ was the rate of success, $n S$ referred to the number of successful performances, and $n T t$ was the number of trials. The rate of consistency of performance was computed by calculating $C V=s / m$, where $C V$ was the rate of variability, $s$ referred to the standard deviation, and $m$ was the arithmetic mean.

To consider the effects of self-talk on learning, Friedman ANOVAs were run on the data from each group in order to verify intra-group differences, and the Kruskall-Wallis test was used for comparisons between the groups in the four blocks of trials (the first and last acquisition, and transfer and retention tests). These blocks of trials allowed us to assess changes in performance from the beginning to the end of the practice, and to assess the permanent and generalizable effects of the learning. In order to diminish the chance of the type I error occurrence, the Bonferroni procedure was applied to each Friedman ANOVA. The observed significant effects were followed up using Wilcoxon and MannWhitney U tests. These analyses were based on Shapiro-Wilk's W and Bartlett's tests of normality and homogeneity of variance. For all analyses the level of significance was set at $p<.05$, using STATISTICA ${ }^{\circledR} 12.0$ software (Stat Soft Inc., Tulsa, USA).

\section{Results}

\section{Performance success rate}

Figure 2 illustrates the average rate of successful performances for each experimental group in the acquisition phase (first and last block), and in the transfer and retention tests. It can be seen that all groups presented an improvement in performance related to the acquisition phase and the maintenance of the achieved levels in the learning tests. In all, the Friedman ANOVAs confirmed these observations: ball $\left(\mathrm{c}^{2}[\mathrm{n}=14, \mathrm{df}=3]=23.31, \mathrm{p}<.01\right)$, bounce $\left(\mathrm{c}^{2}[\mathrm{n}=14\right.$, $\mathrm{df}=3]=19.70, \mathrm{p}<.01)$, hit $\left(\mathrm{c}^{2}[\mathrm{n}=14, \mathrm{df}=3]=27.61\right.$, $\mathrm{p}<.01)$, ready $\left(\mathrm{c}^{2}[\mathrm{n}=14, \mathrm{df}=3]=20.97, \mathrm{p}<.01\right)$, whole $\left(\mathrm{c}^{2}[\mathrm{n}=14, \mathrm{df}=3]=19.14, \mathrm{p}<.01\right)$, and control $\left(\mathrm{c}^{2}[\mathrm{n}=14\right.$, $\mathrm{df}=3]=22.24, \mathrm{p}<.01)$. The Wilcoxon test pointed out that for all groups the rate of performance success in the first acquisition block was inferior to the other blocks $(\mathrm{p}<.01)$. It was also verified that in the retention test, the hit group had a lower rate of success than in the last acquisition and transfer blocks $(\mathrm{p}<.05)$. In addition, the ready and control groups had lower success rates in the transfer test than in the last acquisition block $(\mathrm{p}<.05)$.

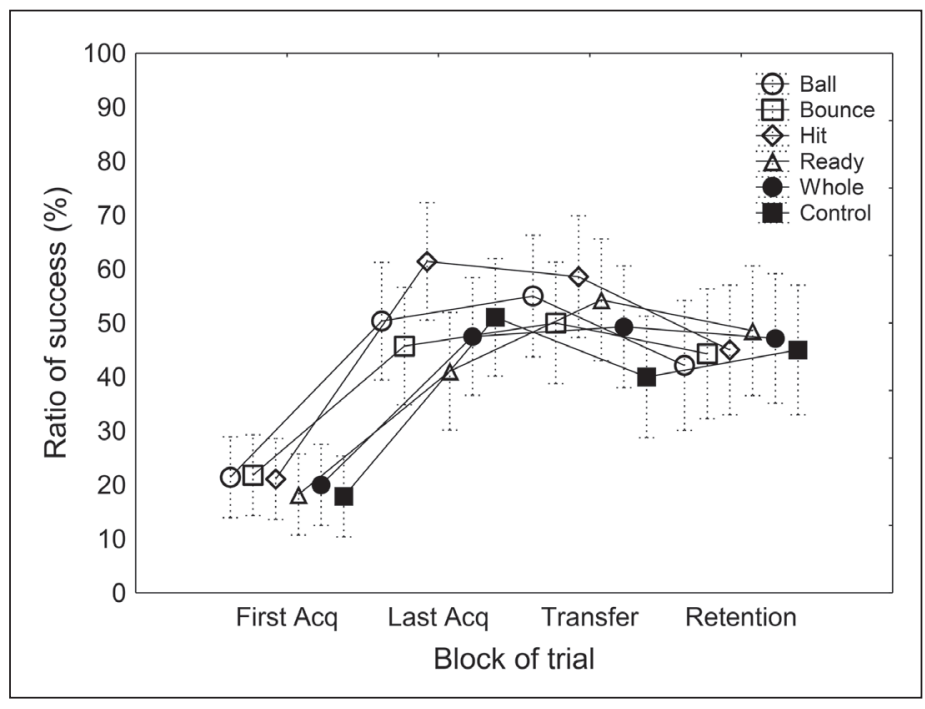

Figure 2. Means of success rate of the self-talk (ball, bounce, hit, ready, and whole) and control groups, in the first and last acquisition blocks (FirstAcq and LastAcq, respectively) and in the transfer and retention tests.

Concerning the inter-group analyses, a Kruskall-Wallis ANOVA showed no significant differences between the groups in all blocks of trials: first acquisition block $(\mathrm{H}(5, \mathrm{n}=84)=0.37$, $\mathrm{p}>.05)$, last acquisition $(\mathrm{H}(5, \mathrm{n}=84)=8.18, \mathrm{p}>.05)$, transfer $(\mathrm{H}(5, \mathrm{n}=84)=5.15, \mathrm{p}>.05)$, and retention $(\mathrm{H}(5, \mathrm{n}=84)=0.94, \mathrm{p}>.05)$. 


\section{Performance consistency rate}

Figure 3 illustrates the average of the rate of variability of performance for each experimental group in the acquisition phase (first and last block), and in the transfer and retention tests. Similar to previous studies, all groups seemed to present an improvement in performance related to the acquisition phase and the maintenance of the achieved levels in the learning tests. Friedman ANOVAs revealed the following effects for all groups: ball $\left(\mathrm{c}^{2}[\mathrm{n}=13, \mathrm{df}=3]=25.76, \mathrm{p}<.01\right)$, bounce $\left(\mathrm{c}^{2}[\mathrm{n}=14\right.$, $\mathrm{df}=3]=20.90, \mathrm{p}<.01)$, hit $\left(\mathrm{c}^{2}[\mathrm{n}=12, \mathrm{df}=3]=29.33\right.$, $\mathrm{p}<.01)$, ready $\left(\mathrm{c}^{2}[\mathrm{n}=14, \mathrm{df}=3]=22.83, \mathrm{p}<.01\right)$, whole $\left(\mathrm{c}^{2}[\mathrm{n}=12, \mathrm{df}=3]=16.17, \mathrm{p}<.01\right)$, and control $\left(\mathrm{c}^{2}[\mathrm{n}=12\right.$, $\mathrm{df}=3]=16.00, \mathrm{p}<.01)$. With the exception of the control group, the Wilcoxon test pointed out that for the remaining groups the rate of variability of performance in the first acquisition block was higher than in the other blocks $(\mathrm{p}<.01)$. It was also verified that in the transfer and retention tests the ready group had a higher rate of variability than in the last acquisition block $(\mathrm{p}<.05)$. Finally, in the control group the rate of variability diminished only from the first to the last acquisition block $(\mathrm{p}<.05)$.

Concerning the inter-group analyses, a Kruskall-Wallis ANOVA showed no significant differences between the groups in all blocks of trials: first acquisition block $(\mathrm{H}(5, \mathrm{n}=77)=1.41$, $\mathrm{p}>.05)$, last acquisition $(\mathrm{H}(5, \mathrm{n}=84)=8.18, \mathrm{p}>.05)$, transfer $(\mathrm{H}(5, \mathrm{n}=84)=5.15, \mathrm{p}>.05)$, and retention $(\mathrm{H}(5, \mathrm{n}=84)=5.15, \mathrm{p}>.05)$.

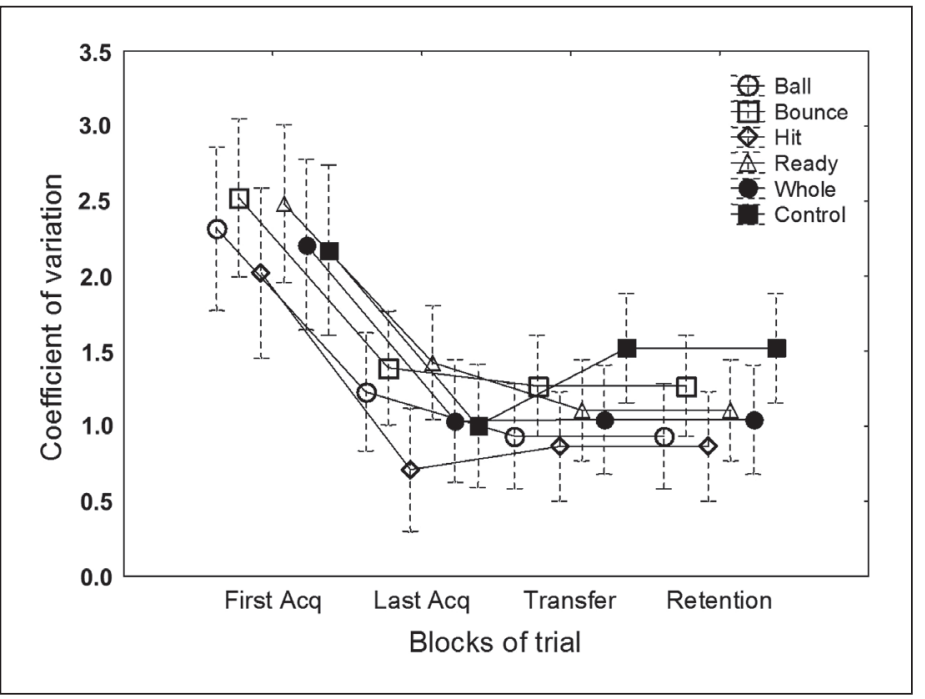

Figure 3. Means of rate of consistency of the self-talk (ball, bounce, hit, ready, and whole) and control groups, in the first and last acquisition blocks (FirstAcq and LastAcq, respectively) and in the transfer and retention tests.

\section{Discussion and conclusions}

The results of this study did not provide support for our hypotheses since all groups learned similarly, that is, they improved their performances during the acquisition phase and maintained their improvement throughout the learning tests. Beginner learners who practised with either one, four, or without self-talk cue did not differ in performance in the retention and transfer tests. In addition, the results did not give support to the hypothesis that practice with self-talk would be more effective than that without self-talk (Hatzigeorgiadis, et al., 2004, 2011).

These results were explained based on the two main explanatory hypotheses. First, one might argue that beginners have informational needs other than those proposed to be supplied by the self-talk: directing attention to relevant aspects of the task and decreased attentional overload. It is well known that there was a negative correlation between practice and the requirements of attention (Schneider \& Shiffrin, 1977). Nevertheless, participants in the present experiment had no previous experience with the task. Considering this, general instructions given to all groups appear to have been sufficient for learning, but not to be complemented with the specific self-talks. This idea is supported by the results of Denardi and Corrêa (2013) who investigated the learning of pirouette in ballet through instruction with an emphasis on specific cues. They found no difference between their cue groups and the control group, which received only general instructions for the task.

Furthermore, in spite of learners having become familiar with the task before starting the systematic practice, the specific information conveyed to participants in the form of self-talk may have been provided at a moment in which a learner needed more information about the general idea of the motor action or about the interaction of its components. Specifically, the main models of learning stages point to a need for the beginning learners to understand general rather than specific aspects of the task in the early stages of learning (e.g. Adams, 1971; Fitts \& Posner, 1967; Gentile, 1972). At this stage, they strive to identify the task's goal and to understand general notions concerning the movement pattern in order to elaborate an action plan (Magill, 2010). Thus, our results do not support those of previous studies indicating that self-talk would mainly benefit the acquisition of motor skills in the early stages of learning (Cutton \& Landin, 2007; Hatzigeorgiadis, et al., 2011; Landin, 1994; Zervas, et al., 2007). In fact, it is important to highlight that the study showing benefits of self-talk on retention of motor learning did not involve beginning learners (Zetou, et al., 2012), which supports our findings. In the previous study, subjects with two years of experience practised the volleyball service skill. 
Second, self-talk may have no effect on learning. As we mentioned, although self-talk literature points to the effects on learning, studies have not consistently considered retention and/or transfer tests in their experimental designs. Retention and transfer tests function to separate the temporary effects of an independent variable (e.g. self-talk) on performance from the permanent and generalizable effects of learning (Schmidt \& Lee, 2011). Specifically, retention is a complementary process to forgetfulness. It concerns the preservation of knowledge or information, and forgetfulness to the loss of memory (Singer, 1980). A person would be unable to learn if he/she could not retain what he/ she had learned. Retention can be defined as the persistence of proficiency in a motor skill after a period without practicing it (Fischman, Christina, \& Vercruyssen, 1982). On the other hand, transfer involves the application of learning a particular task or situation, on the performance of some other task identified as a criterion task (Schmidt \& Lee, 2011). Transfer involves generalization, and can be defined as the influence of previous learning on the performance of new skills (Fischman, et al., 1982). To put it in another way, transfer arises every time learners practice a version of a given task with the idea that the learning achieved will be useful in some other version of the task (Santos, Bastos, Souza, \& Corrêa, 2014). Finally, based on these statements and the fact that no difference between the experimental groups was observed in retention and transfer tests, it is possible to think that the self-talk did not supply the learning with additional positive effect. This conclusion opens a new window for interpreting the self-talk effects in contexts of motor skills.

Interestingly, maybe this conclusion can be extended to beyond motor learning. This is because, independently of learning tests, recent studies have shown similar effects of different kinds of self-talk on performance. For instance, Weinberg et al. (2012) investigated effectiveness of interaction between type and control of self-talk on one-mile run performance. Specifically, they combined the instructional, motivational, and instructional-motivational self-talks with the assigned and self-controlled selftalks. The results have shown no significant diffe- rences between groups in the post-test. Similar to our study, they have only shown improvement in performance from pre- to post-test.

Recently, Van Raalte and colleagues (2016) have proposed a useful model for investigating and advancing the comprehension of the self-talk phenomenon. Their sport-specific model of self-talk describes the interaction of self-talk with personal and situational factors, systems 1 and 2, and behaviour. Personal factors involve the individual stylus, personal preferences and personality traits. Task characteristics and social/contextual circumstances are related to situational factors. Systems 1 and 2 involve, respectively, affect, motivation, and anxiety, and cognitive mechanisms and processes. Finally, the behaviour involves those intentional and observable specific actions (e.g. sport-specific motor skills). According to this model, system 2 is the main component responsible for information processing involved in the self-talk, and for directing attention and consequent enhancement of performance. An important feature of this system is that it has limited resource/capacity, and therefore, might become dysfunctional because of overuse or excessive effort. Based on this statement, the sportspecifc model of self-talk could support our findings that too many cues could lead to attentional overload due to exhaust of system 2 .

In summary, the findings of this study allow us to conclude that the practice of tennis forehand with and without self-talk had similar effects on the beginners' learning. Additionally, the self-talk of four cues led to similar learning compared to the self-talk of only one cue. It is important to highlight that self-talk did not hinder learning the motor skill, as it was observed for all self-talk groups. However, for future studies, we suggest that the self-talk cues be tested by inserting them during the associative phase of learning, when the learner has already acquired the movement idea, that is, after an "extended baseline". Furthermore, although the rate of success we used allowed us to access motor learning, it was calculated based on hitting the target. Thus, future studies could explore other performance measures (e.g. radial error) as complementary measures.

\section{References}

Adams, J.A. (1971). A closed-loop theory of motor learning. Journal of Motor Behavior, 3(2), 111-150.

Burton, D., Gillham, A., \& Glenn, S. (2011). Motivational styles: Examining the impact of personality on the selftalk patterns of adolescent female soccer players. Journal of Applied Sport Psychology, 23(4), 413-428. doi: 10.1080/10413200.2011.568469

Cutton, D.M., \& Landin, D. (2007). The effects of self-talk and augmented feedback on learning the tennis forehand. Journal of Applied Sport Psychology, 19(3), 288-303.

Denardi, R.A., \& Corrêa, U.C. (2013). Effects of instructional focus on learning a classical ballet movement, the pirouette. Journal of Dance Medicine \& Science, 17(6), 18-23. 
Edwards, W.H. (2010). Motor learning and control: From theory to practice. Belmont, CA: Wadsworth.

Fischman, M.G., Christina, R.W., \& Vercruyssen, M.J. (1982). Retention and transfer of motor skills: A review for the practitioner. Quest, 33(2), 181-194.

Fitts, P.M. \& Posner, M.I. (1967). Human performance. Oxford: Brooks/Cole.

Gentile, A.M. (1972). A working model of skill acquisition with application to teaching. Quest, 17(1), 3-23.

Hardy, J. (2006). Speaking clearly: A critical review of the self-talk literature. Psychology of Sport and Exercise, 7(1), 81-87.

Hardy, J., Hall, C.R., \& Hardy, L. (2004). A note on athletes' use of self-talk. Journal of Applied Sport Psychology, $16(3), 251-257$.

Hatzigeorgiadis, A., Theodorkis, Y., \& Zourbanos, N. (2004). Self-talk in the swimming pool: The effects of self-talk on thought content and performance on water-polo tasks. Journal of Applied Sport Psychology, 16(2), 138-150.

Hatzigeorgiadis, A., Zourbanos, N., Galanis, E., \& Theodorakis, Y. (2011). Self-talk and sports performance: A metaanalysis. Perspectives on Psychological Science, 6(4), 348-356.

Kahneman, D. (1973). Attention and effort. Englewood Cliffs, NJ: Prentice-Hall.

Landin, D. (1994). The role of verbal cues in skill learning. Quest, 46, 299-313.

Magill, R.A. (2010). Motor learning and control: Concepts and applications ( $9^{\text {th }}$ ed.). New York: McGraw-Hill.

Pasetto, S.C., Araújo, P., \& Corrêa, U.C. (2006). Efeitos de dicas visuais na aprendizagem do nado crawl para alunos surdos. [Effects of visual cues on learning the front crawl by deaf students. In Portuguese.] Revista Portuguesa de Ciências do Desporto, 6(3), 14-19.

Santos, J.J., Bastos, F.H., Souza, T.O., \& Corrêa, U.C. (2014). Contextual interference effect depends on the amount of time separating acquisition and testing. Advances in Physical Education, 4(2), 102-109.

Schmidt, R.A., \& Lee, T.D. (2011). Motor learning and control: A behavioral emphasis (5 ${ }^{\text {th }}$ ed.). Champaign, IL: Human Kinetics.

Schneider, W., \& Shiffrin, R.M. (1977). Controlled and automatic human information processing: II. Perceptual learning, automatic attending, and a general theory. Psychological Review, 84(2), 127-190.

Singer, R.N. (1980). Motor learning and human performance: An application to motor skills and movement behaviors ( $3^{\text {rd }}$ ed.). New York: MacMillan.

Theodorakis, Y., Weinberg, R., Natsis-Douma, I., \& Kazakas, P. (2000). The effects of motivational versus instructional self-talk on improving motor performance. Journal of Sports Psychology, 14(3), 253-271.

Van Raalte, J.L., Vincent, A., \& Brewer, B.W. (2016). Self-talk: Review and sport-specific model. Psychology of Sport and Exercise, 22, 139-148. doi:10.1016/j.psychsport.2015.08.004

Weinberg, R., Miller, A., \& Horn, T. (2012). The influence of a self-talk intervention on collegiate cross-country runners. International Journal of Sport and Exercise Psychology, 10(2), 123-134. doi: 10.1080/1612197X.2012.645135

Zervas, Y., Stavrou, N.A., \& Psychountaki, M. (2007). Development and validation of the self-talk questionnaire (S-TQ) for sports. Journal of Applied Sport Psychology, 19(2), 142-159. doi: 10.1080/10413200601185156

Zetou, E., Vernadakis, N., \& Bebetsos, E. (2014a). The effect of instructional self-talk on performance and learning the backstroke of young swimmers and on the perceived functions of it. Journal of Physical Education and Sport, 14, $27-35$.

Zetou, E., Vernadakis, N., Bebetsos, E., \& Liadakis, N. (2014b). The effect of self-talk on tae-kwon-do skills' learning of novice athletes and perceived use of it. Journal of Human Sport and Exercise, 9(1), 124-135.

Zetou, E., Vernadakis, N., Bebetsos, E., \& Makraki, E. (2012). The effect of self-talk in learning the volleyball service skill and self-efficacy improvement. Journal of Human Sport and Exercise, 7(4), 794-805.

Ziegler, S.G. (1987). Effects of stimulus cueing on the acquisition of groundstrokes by beginning tennis players. Journal of Applied Behavior Analysis, 20(4), 405-411.

Zourbanos, N., Theodorakis, Y., \& Hatzigeorgiadis, A. (2006). Coaches' behaviour, social support, and athletes selftalk. Hellenic Journal of Psychology, 3, 117-133.

Submitted: January 14, 2016

Accepted: April 27, 2016

Correspondence to:

Assoc. Prof. Umberto Cesar Corrêa, Ph.D.

School of Physical Education and Sport

University of São Paulo

Av. Mello Moraes, 65, Cidade Universitária

São Paulo, SP, Brazil CEP 05508-030

Phone: 55-11-3091 3136

Fax: 55-11-3813 5921

E-mail: umbertoc@usp.br 